\title{
O ESTATUTO DO ESTRANGEIRO E A MUDANÇA DA FUNDAMENTAÇÃO DA POLÍTICA MIGRATÓRIA BRASILEIRA
}

\section{THE FOREIGNER ACT AND THE CHANGE OF FUNDAMENTATION OF BRAZIL'S MIGRATORY POLICY}

Recebido: 22.03.2017

Aprovado: 19.10.2017

Pedro Henrique Gallotti Kenicke*
Bruno Meneses Lorenzetto**

RESUMO: O presente trabalho pretende demonstrar que a lei 6.815/198o, o conhecido Estatuto do Estrangeiro, é não apenas a lei regulamentadora da entrada e saída de migrantes internacionais no país, mas, também, o vértice ideológico das ações governamentais para a promoção e proteção dos migrantes. Apresenta-se a lei 6.815/1980 como um dos últimos legados legislativos do regime civil-militar que governou o Brasil entre 1964 e 1985. Seu fundamento ultranacionalista, calcado na antiga doutrina da segurança nacional, determina a diretriz da política pública das migrações do Brasil. Desse modo, deve o Estatuto do Estrangeiro ser revogado em benefício de novo Estatuto das Migrações justificado no paradigma do desenvolvimento humano.

Palavras-chave: Estatuto do estrangeiro. Migração international. Segurança nacional. Políticas públicas.

\begin{abstract}
This essay intends to demonstrate that the Act 6.815/1980, the famous Foreigner Act, not only is the regulatory law for entering and exiting of international migrants in the State, but also as the ideological core of governmental actions to the promotion and protection of migrants. It shows the Act $6.815 / 1980$ as one of the civil-military regime's last legal legacies, which had ruled Brazil between 1964 and 1985. The ultranationalist fundament of this law, set up on the grounds of the old national security doctrine, determines the guideline of Brazilian migrations policy. Therefore, it is necessary the repeal of the Foreigner Act to benefit a new Migrations Act justified by the human development paradigm.
\end{abstract}

Keywords: Foreigner act. International migration. National security. Human development.

\footnotetext{
* Mestre em Direito do Estado pela Universidade Federal do Paraná (UFPR). Membro da Comissão de Direito Internacional da OAB-PR. Advogado no escritório Clèmerson Merlin Clève Advogados Associados. E-mail: < pedro@ cleveadvogados.com.br $>$.

** Professor de Direito da Pontifícia Universidade Católica do Paraná. Coordenador do Programa de Mestrado em Direito (Direitos Fundamentais e Democracia) e Professor da Graduação do Centro Universitário Autônomo do Brasil - UniBrasil. Visitng Scholar na Columbia Law School, Columbia University, New York (2013-2014). Doutor em Direito pela UFPR na área de Direitos Humanos e Democracia (2010-2014). Mestre em Direito pela UFPR na área do Direito das Relações Sociais (2008-2010). Graduado em Direito pela Pontifícia Universidade Católica do Paraná (2003-2007). Bolsista pela CAPES durante o Mestrado na UFPR. Desenvolve suas pesquisas na área de Direito, com ênfase em Direito Constitucional, Teoria do Direito e Teoria do Estado. E-mail < bruno_lorenzetto@yahoo.com.br >.
} 


\section{INTRODUÇÃO}

A lei 6.815/1980 representa a última frente legal para a política migratória nacional e foi introduzida na ordem jurídica brasileira durante a vigência da Constituição de 1967/1969. ${ }^{1}$ Disso se pode constatar que a referida legislação é produto do período político autoritário que vigorou no país entre 1964 e 1985. A lei, denominada Estatuto do Estrangeiro, tem sua base fundada na antiga doutrina da segurança nacional, ideologia que contribuiu para o estabelecimento e manutenção do governo da ditadura e de seus respectivos discursos justificatórios (BORGES, 2004, p. 31). Trata-se de uma normativa nacional com pretensão de disciplinar a vida do estrangeiro no Brasil, por isso, regula direitos e deveres, além de ter sido estabelecida para orientar as ações da política pública migratória do país.

É possível dizer, então, que o diploma legal se apresenta como o vértice do sistema jurídico migratório que o governo brasileiro aplica por meio de sua ossatura institucional. Em decorrência das políticas esposadas pelo Estatuto do Estrangeiro, pode-se observar que o Poder Executivo se encontra, em função da referida lei, impedido de desenhar uma política migratória integral, com capacidade para cuidar do imigrante - incluídos os asilados -, assim como do emigrante, a partir das coordenadas estabelecidas pelos desafios do nosso tempo. O referido diagnóstico impulsiona as demandas a respeito da reformulação legislativa que se faz necessária a respeito do tratamento nacional dispensado aos não nacionais.

Vive-se no Brasil, quando se trata da legislação relativaàs migrações internacionais, um notável descompasso. Ainda somos governados por dispositivos que não apenas foram incorporados ao nosso ordenamento nos "anos de chumbo", mas que, efetivamente, refletem o conjunto de discursos daquele momento histórico. Note-se que nas décadas de 1980 e 1990, após a fundação da Nova (ou Quarta) República, o Brasil passou por um momento que Gelson Fonseca Junior denominou de "renovação de credenciais", pois foi o período da desconstrução das instituições da ditadura e da construção de novas em consonância com o direito internacional dos direitos humanos (FONSECA JR., 2004). Exemplo claro disso, para ficar no âmbito das migrações, foi a edição da lei 9.474, de 22 de julho de 1997, que implementou o Estatuto dos Refugiados no Brasil. O Estatuto do Estrangeiro, entretanto, sobreviveu atrelado a um conjunto de ideais que refletem a doutrina de segurança nacional, que observa o estrangeiro como uma ameaça potencial ao país.

Cumpre, agora, sob a égide do regime democrático e com fundamento nos direitos humanos, observada a Constituição de 1988 como marco jurídico fundamental, providenciar novo estatuto que preze, acima de tudo, pela promoção dos direitos dos migrantes. A fim de que isso aconteça, a nova lei de migração deve ser compreendida não

1 A Constituição de 1967 dispôs sobre alguns tópicos quanto ao migrante, incluindo o art. 153 dos Direitos e Garantias Individuais. No entanto, André de Carvalho Ramos explica que "o fluxo imigratório começou a perder fôlego e o tema passou a não mais figurar na agenda política” (RAMOS, André de Carvalho. Direitos dos estrangeiros no Brasil: a imigração, direito de ingresso e is direitos dos estrangeiros em situação irregular. In: SARMENTO, Daniel; IKAWA, Daniela; PIOVESAN, Flávia. Igualdade, diferença e direitos humanos. Rio de Janeiro: Lumen Juris, 20o8, p. 729). 
apenas como instrumento normativo que dispõe sobre os procedimentos de controle de entrada e saída e das condições de permanência e expulsão do migrante, mas, antes, como o eixo central, político e ideológico, determinante da emergência de uma renovada política pública migratória do Brasil.

\section{O CONCEITO DE POLÍTICA PÚBLICA E A POLÍTICA PÚBLICA MIGRATÓRIA NO BRASIL}

Maria Paula Dallari Bucci lembra que uma política pública pode ter diferentes bases legais. Entretanto, a autora demonstra que é necessário preencher algumas condições para a identificação das "expressões jurídicas das políticas públicas”, como notar que nem todo plano nacional denominado "política" é considerado um programa de ação governamental, este identificado como política pública, e que nem todo direito é permeado pela política - apenas aquele que seja policy ou programa de governo (BUCCI, 2006, p. 1-11).

Desse modo, para Bucci, as políticas públicas constituem-seem metas, resultadose diretrizes, conformam um conjunto de medidas coordenadas, cujo escopo é movimentar a máquina do governo para realizar certo objetivo de ordem pública ou a concretização de um direito. Além disso, a política pública pode também ser reconhecida como ação estratégica ao incorporar "elementos sobre a ação necessária e possível naquele momento determinado, naquele conjunto institucional” e os projetar para o futuro mais próximo (BUCCI, 2006, p. 14-19).

Nesse contexto, verifica-se que temos, entre nós, uma política pública brasileira de migrações. Ela, todavia, está circunscrita a um modelo ultrapassado e desafia mudanças. Aliás, diante da falta de legitimidade do diploma legislativo que lhe dá suporte, podese afirmar que não há no Brasil, desde a promulgação da Constituição Federal de 1988, uma política pública das migrações homogênea que guarde sintonia com os objetivos e princípios constitucionais. O que se tem, na verdade, é uma política que tem implicado "desgovernança" institucional, ${ }^{2}$ uma desgovernança decorrente da confusa desconcentração de órgãos que cuidam da situação dos migrantes, sendo incrementada pela falta de uma nova legislação racionalizadora da política das migrações.

O governo, perante a falta de um novo Estatuto das Migrações para pautar sua política migratória, ${ }^{3}$ executa suas tarefas como pode, muitas vezes amparado em atos

2 Termo usado pelo representante do Departamento de Estrangeiros do Ministério da Justiça João Guilherme Lima Granja Xavier da Silva, no IV Seminário da Cátedra Sérgio Vieira de Mello (UFPR: 30.09.2013 - 1º.10.2013), para determinar a situação atual dos órgãos destinados a cuidar da migração no país.

3 Em 2017, a nova Lei de Migração (13.445/2017) foi sancionada. Ela representa o turning point na legislação sobre o migrante no Brasil e segue a fundamentação induzida pela Constituição de 1988: o respeito e a proteção à dignidade da pessoa humana juntamente com a busca pelo desenvolvimento humano. A partir dela, será possível reformular a Política Migratória Brasileira, como de fato está previsto em suas disposições transitórias: "Art. 120 A Política Nacional de Migrações, Refúgio e Apatridia terá a finalidade de coordenar e articular ações setoriais implementadas pelo Poder Executivo federal em regime de cooperação com os Estados, o Distrito Federal e os Municípios, com participação de organizações da sociedade civil, organismos internacionais e entidades privadas, conforme regulamento. $\S 1^{0}$ Ato normativo do Poder Executivo federal poderá definir os objetivos, a organização e a estratégia de coordenação da Política Nacional de Migrações, Refúgio e Apatridia. $§ 2^{\circ}$ Ato normativo do Poder Executivo federal poderá estabelecer planos nacionais e outros instrumentos para a efetivação dos objetivos desta Lei e a coordenação entre órgãos e 
normativos infralegais como os decretos da Presidência da República, as resoluções do Conselho Nacional de Imigração, bem como as portarias da Polícia Federal edo Ministério do Trabalho e Emprego. ${ }^{4}$ Ao se entender que as políticas públicas visam à racionalização técnica da ação do poder público para a realização de objetivos determinados (BUCCI, 2006, p. 25-31), percebe-se que não há uma política migratória brasileira centralizada e racional que possa ser designada como política pública. Logo, a política migratória calcada em dispositivos normativos ultrapassados não corresponde aos novos desafios, econômicos e sociais que se abrem com a distinta realidade social do Brasil e sua projeção internacional.

\section{O ESTATUTO DOESTRANGEIROCOMO VÉRTICE DA POLÍTICA PÚBLICA MIGRATÓRIA BRASILEIRA}

O Estatuto do Estrangeiro guia as ações das políticas públicas do governo relacionadas com ocontroleda entrada eda saídade migrantes. Sua baseultranacionalista, ${ }^{5}$ calcada na ideologia da antiga doutrina da segurança nacional, ${ }^{6}$ representa entrave para o estabelecimento de relações migratórias consistentes e para a direção de uma política pública migratória inclusiva, que dê oportunidades para o desenvolvimento das capacidades do migrante. O Estatuto do Estrangeiro define o migrante por exclusão (RAMOS, 2008, p. 748) e regula sua entrada a partir de condições arbitrárias fundamentadas em nocividade "à ordem pública ou aos interesses nacionais", 7 ou conforme seja a presença do migrante inconveniente "no território nacional, a critério do

colegiados setoriais. $\S 3^{\circ}$ Com vistas à formulação de políticas públicas, deverá ser produzida informação quantitativa e qualitativa, de forma sistemática, sobre os migrantes, com a criação de banco de dados." Dessa maneira, a Lei de Migração passa ser, a partir de novembro de 2017, o novo norte da política migratória, porque revogou o Estatuto do Estrangeiro.

4 No mesmo sentido, SICILIANO, André Luiz. A política migratória brasileira: limites e desafios. São Paulo: USP-IRI, 2013, p. 32. O autor observa que "há uma profusão de dispositivos, descoordenados, que foram editados de maneira isolada, para responder a questões pontuais de conjuntura, de modo que não há coesão nem coerência entre as normas que demarcam a política brasileira para as migrações." (p. 33).

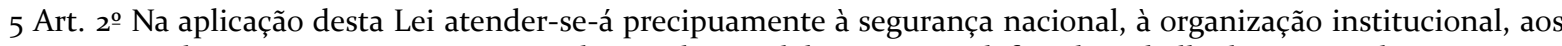
interesses políticos, sócio-econômicos e culturais do Brasil, bem assim à defesa do trabalhador nacional.

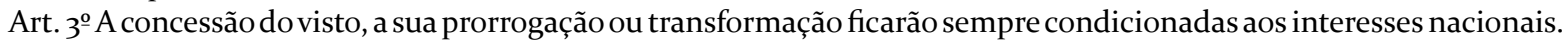

6 "Vinculando segurança externa a segurança interna, os formuladores da Doutrina no Brasil criam no imaginário dos estagiários (é como são chamados, ainda hoje, os alunos da Escola) a concepção de que o inimigo interno está infiltrado em toda a sociedade brasileira, agindo organizadamente para tomar o poder e, assim, transformar o Brasil num República totalitária. O inimigo interno, isto é, todo aquele que não se pronuncia a favor do regime e dos ideais revolucionários, seduzido por ideologias estranhas e apoiado por forças externas (comunismo internacional), é um mal que deve ser extirpado, pois ele coloca em perigo a segurança do país e, por conseqüência, o seu desenvolvimento político, econômico e social." (BORGES, Nilson. A doutrina da segurança nacional e os governos militares. In: FERREIRA, Jorge; DELGADO, Lucilia de Almeida Neves (Coords.). O Brasil republicano: o tempo da ditadura - regime militar e movimentos sociais em fins do século XX. 1. 4, Rio de Janeiro: Civilização Brasileira, 2004, p. 36-37.

7 Art. $7^{\text {o }}$ Não se concederá visto ao estrangeiro:

I - menor de 18 (dezoito) anos, desacompanhado do responsável legal ou sem a sua autorização expressa;

II - considerado nocivo à ordem pública ou aos interesses nacionais;

III - anteriormente expulso do País, salvo se a expulsão tiver sido revogada;

IV - condenado ou processado em outro país por crime doloso, passível de extradição segundo a lei brasileira; ou

V - que não satisfaça às condições de saúde estabelecidas pelo Ministério da Saúde. 
Ministério da Justiça”. ${ }^{8}$

Quando editada nos idos da década de 1980, a lei 6.815 foi criticada por diversos "ativistas de direitos humanos, líderes de oposição e pela Igreja Católica" (TIBURCIO, 2008, p. 752), o que levou à alteração decorrente da lei 6.964/1981 que renovou algumas garantias ao migrante em conformidade com o ordenamento jurídico então vigente. Menos de sete anos depois, ocorreu a promulgação da conhecida "Constituição Cidadã”, lei fundamental que preza pela garantia, efetividade e promoção dos direitos fundamentais. Há entre a referida lei e a nova Constituição uma enorme distância de fundamentos que ainda não foi resolvida quase três décadas após a inauguração da nova ordem constitucional. ${ }^{9}$

Cumpre, reitere-se, mudar a política migratória brasileira, por meio da aprovação de novo dispositivo regulamentador, com a finalidade de prestigiar o desenvolvimento humano e, portanto, a Constituição e os tratados internacionais de direitos humanos. A análise se pauta pelos mecanismos próprios da linha doutrinária denominada 'dogmática constitucional' emancipatória onde o foco

(...) não é o Estado, mas, antes, a pessoa humana exigente de bem-estar físico, moral e psíquico. Esta dogmática (...) não é positivista, embora respeite de modo integral a normatividade constitucional, emergindo de um compromisso principialista e personalizador para afirmar, alto e bom som, que o Direito Constitucional realiza-se, verdadeiramente, na transformação dos princípios constitucionais, dos objetivos fundamentais da República Federativa do Brasil e dos direitos fundamentais em verdadeiros dados inscritos em nossa realidade existencial (CLÈVE, 2012, p.16).

Grandes passos têm sido dados à questão, é preciso que se diga, como, por exemplo, a promulgação, pelo Decreto n. 8.101, de 6 de setembro de 2013, da Resolução n. 1.105, de 30 de novembro de 2004 que aprova a constituição da Organização Internacional para as Migrações (OIM) e o ingresso do Brasil nela, o que demonstra corrente interesse do Estado ao tema. Veja-se, também, que a adesão do país a tal organização internacional demonstra a vontade estatal de discutir abertamente tal temática complexa que afeta todos os membros da comunidade internacional. ${ }^{10}$

É preciso, portanto, que se edite nova lei nacional, novo estatuto que reoriente as diretrizes da política pública das migrações. ${ }^{11}$ Para que isso ocorra, o país deve se abrir

8 Art. 26. O visto concedido pela autoridade consular configura mera expectativa de direito, podendo a entrada, a estada ou o registro do estrangeiro ser obstado ocorrendo qualquer dos casos do artigo $7^{\circ}$, ou a inconveniência de sua presença no território nacional, a critério do Ministério da Justiça.

9 Ressalta-se, também, que a decaída de imigrações ao Brasil, e, ainda, a transformação do país em emigrador nos anos 1980 e 1990 influenciou a inércia legislativa a partir da promulgação da Constituição de 1988.

1o Clèmerson Merlin Clève já afirmava em 2004 que “[o] Brasil não alcançará, nesse mundo conturbado, êxito sem uma articulação muito bem feita, entre políticas nacionais de defesa dos seus interesses e uma política internacional de apoio aos foros multilaterais de discussão dos problemas de alcance mundial" (CLĖVE, Clèmerson Merlin. Direito Constitucional, novos paradigmas, constituição global e processos de integração. SAMPAIO, José Adércio Leite (Org.). 15 anos de Constituição. Belo Horizonte: Del Rey, 2004, p. 410)

11 A já referida Lei n. 13.445/2017 veio cumprir esse papel, pois revogou globalmente a Lei n. 6.815/1980 e a Lei 818/1949. Em vigência a partir de novembro de 2017, a Lei de Migração exigirá regulamentação calcada no respeito aos direitos fundamentais do migrante. Ela veicula entendimento de que o Brasil deve tratar os imigrantes do mesmo modo 
por meio de uma política migratória balizada pela legislação federal consentânea à Constituição. ${ }^{12}$

\section{DA NECESSIDADE DA ALTERAÇÃO LEGISLATIVA}

Se a lei 6.815/1980 não corresponde mais aos ditames do ordenamento jurídico brasileiro, que preza pela promoção e proteção dos direitos humanos, entende-se que deve ser providenciado um novo diploma legislativo, em substituição ao pensamento institucional construído no primeiro período da Guerra Fria e mantido no Brasil até meados da década de 1980.

Situada entre os anos de 1947 e 1955, o primeiro período da Guerra Fria instituiu a relação "quente" do conflito (SARAIVA, 2008, p.197-199). Foi o momento de conceituação e identificação da nova ordem internacional após a Segunda Guerra Mundial, quando o antagonismo entre leste e oeste era mais intenso. Nessa fase, criou-se o conceito de "superpotência" e foram estabelecidas as áreas de influência dos dois pensamentos sociais e econômicos que, na época, dividiram o mundo. São exemplos do período as ideias de George Kennan e Churchill sobre a "ameaça vermelha” na Europa, o plano de reconstrução da Europa por George Marshall e a constituição da Doutrina Truman que levaria à origem da Organização do Tratado do Atlântico Norte (OTAN).

Tal pensamento se espalhou pelas Américas, em prol da ideia de segurança coletiva. Perante esse contexto, em 1949, foi fundada a Escola Superior de Guerra, instituição criadora e reprodutora da versão brasileira da doutrina da segurança nacional e do pensamento militar que impulsionaria a ação do golpe de estado em 1964 (COMBLIN, 2004, p.35-38). Ademais, não somente a lei 6.815/1980, mas, também, a lei 7.170/1983 (a lei de segurança nacional), comprova a culminância desse pensamento à época.

Dessa forma, entende-se imprescindível a discussão e implementação de novo paradigma para as políticas migratórias nacionais, para que este não mais reflita um cenário geopolítico ultrapassado. O novo paradigma precisa estabelecer pilares institucionais que possibilitem o diálogo contínuo do Estado com a sociedade civil, o atendimento das minorias representadas pelos migrantes já integrados à sociedade

como trata os brasileiros, sem qualquer discriminação que não seja expressamente explícita na Constituição e na legislação infraconstitucional. É preciso respeitar os migrantes no Brasil para poder exigir o mesmo respeito dos brasileiros no exterior. Aliás, é o que indica expressamente a nova Lei de Migração porque prevê capítulo inteiro para o Emigrante brasileiro e as diretrizes para suas políticas públicas. O rol exemplificativo de direitos inscritos na lei 13.445 corresponde aos mesmos direitos garantidos no bloco de constitucionalidade, o que por si só não representa alterações no ordenamento jurídico - veja-se, por exemplo, os direitos previstos no artigo $4^{\text {o }}$ da lei que tem como caput o seguinte: "Art. $4^{\circ}$ Ao migrante é garantida no território nacional, em condição de igualdade com os nacionais, a inviolabilidade do direito à vida, à liberdade, à igualdade, à segurança e à propriedade, bem como são assegurados: (...)". Mas sua edição representa forte simbolismo, porque se alterou a leitura jurídica do migrante a partir da doutrina da segurança nacional para se afirmar o respeito ao outro como pessoa humana em benefício do desenvolvimento humano em geral, mas sem esquecer do desenvolvimento nacional do país.

12 Nesse sentido, afirma Clève: "A autarquia, o fechamento não são mais possíveis, pois o interesse nacional passa hoje pelo fortalecimento da posição do país no plano internacional. As políticas internas e desenvolvimentistas, a defesa intransigente do interesse nacional não se sustentam mais na autarquização, demandando, antes, a conquista de posição privilegiada no mundo globalizado. Por isso afirmar-se que o que vale para a política, também vale para o direito." (CLÈVE, Clèmerson Merlin. Direito Constitucional, novos paradigmas, constituição global e processos de integração. SAMPAIO, José Adércio Leite (Org.). 15 anos de Constituição. Belo Horizonte: Del Rey, 2004, p. 410-411). 
brasileira e a sintonia com os tratados de direitos humanos ratificados pelo país. Isso remete à alternativa proposta do desenvolvimento humano, a concretizar, ao mesmo tempo, o desenvolvimento social do Brasil e o desenvolvimento dos migrantes que aqui estão estabelecidos ou que irão se estabelecer. A noçãode desenvolvimento humano, nesse contexto, refere-se à ação concreta de possibilitar oportunidades e o desenvolvimento de capacidades das pessoas e, por isso, pode ser compreendida como peça fundamental no novo paradigma para a futura lei de migrações. ${ }^{13}$

Para Amartya Sen, teórico do desenvolvimento humano, "a essência da justiça não repousa nem sobre a igualdade de meios (direitos e recursos), nem sobre a igualdade de resultados (nível de bem estar), mas sobre a igual capacidade dos indivíduos de fazer com os meios os resultados que reclamam a sua concepção de vida" (GÉNÉREUX, 2014, p.161). O desenvolvimento é a "expansão de liberdades substantivas" do ser humano, logo "requer que se removam as principais fontes de privação de liberdade: pobreza e tirania, carência de oportunidades econômicas e destituição social sistemática, negligenciados serviços públicos e intolerância ou interferência excessiva dos Estados repressivos" (SEN, 200o, p.17-18). Portanto, o autor defende, para a satisfação das capacidades das pessoas, "um atuar positivo do Estado concretizado através da adoção de políticas públicas capacitantes". ${ }^{14}$

Ademais, "[o] desenvolvimento consiste na eliminação de privações de liberdade que limitam as escolhas e as oportunidades das pessoas de exercer ponderadamente sua condição de agente" e, por conseguinte, para se realizar o desenvolvimento humano é imprescindível a "livre condição de agente das pessoas". O migrante tem garantida sua situação de igualdade com o cidadão brasileiro a partir da proteção legislativa que a política pública migratória lhe proporciona, ao afirmar, portanto, sua liberdade (SEN, 2000, p.10-17).

Providenciada sua segurança jurídica por meio de renovada política migratória, no país que o recebeu, onde o cerne legislativo permite a viragem em busca do desenvolvimento humano, terá o imigrante aptidão para agir e para se expressar como cidadão: escolhendo, sem constrições, participar da economia, do âmbito político (no que a Constituição Federal lhe permitir), ${ }^{15}$ usufruindo dos serviços públicos, tudo sem a sensação de "mal-estar"16 na espera por respostas institucionais e prestações de serviços que condicionariam sua eficácia à sua situação de "estrangeiro".

Dessa maneira, em vindo a ser estabelecido o desenvolvimento humano do migrante no Brasil, espera-se que o desenvolvimento nacional venha a ser incrementado

13 Aqui se utilizam as obras do economista Amartya Sen, como Desenvolvimento como liberdade, A Ideia de Justiça e Desigualdade Reexaminada (SEN, Amartya. Desigualdade reexaminada. trad. Ricardo Doninelli Mendes. 3.ed. Rio de Janeiro: Record, 2012; SEN, Amartya. Desenvolvimento como liberdade. Trad. Laura Teixeira Motta. São Paulo: Companhia das Letras, 200o; SEN, Amartya. The idea of justice. Cambridge: Harvard University, 2009).

14 CLÈVE, Clèmerson Merlin. Temas de direito constitucional. 2.ed. Belo Horizonte: Fórum, 2014, p. 161.

15 E aqui se nota que nenhum estrangeiro, à exceção do cidadão português que requereu tratamento recíproco conforme o Estatuto da Igualdade entre Brasil e Portugal, tem direitos políticos no Brasil.

16 Mal-estar encontrado na sensação de que não há segurança na proteção institucional do Estado, sendo este a causa do fenômeno a partir de sua omissão legal. 
qualitativamente. Nesse sentido, Amartya Sen nota que, no âmbito da argumentação pública,

[...] há claramente fortes razões para não deixarmos de fora as perspectivas e os argumentos apresentados por toda pessoa cuja avaliação seja relevante, quer porque seus interesses estejam envolvidos, quer porque suas opiniões sobre essas questões lançam luz sobre juízos específicos - uma luz que poderia ser perdida caso não se desse a essas perspectivas uma oportunidade para se manifestarem (2011, p.74).

A ideia do "outro", ${ }^{17}$ entendido como diferente do nacional, passa a ter acepção positiva quando se releva sua capacidade crítica, às vezes distinta do cidadão nativo, que pode servir para identificar falhas na estrutura de governo do Estado para com os seus nacionais. Esse intercâmbio cultural, essa troca de pensamentos somente pode ser incrementada se o migrante puder se expressar com segurança.

Lembra Amin Maalouf que o intercâmbio cultural significa que o imigrante não deve esquecer suas raízes culturais, ${ }^{18}$ pois o desenvolvimento nacional está implicitamente ligado à ideia de rede social de migração e esta significa o estabelecimento de relações estreitas entre as comunidades de migrantes com seus países de origem. ${ }^{19}$

Com a formação de fortes vínculos entre as comunidades, há maior abertura de influência entre os Estados. Isso se torna positivo para todos, pois o estreitamento de relações demanda acordos comerciais e de cooperação técnica sustentáveis e, em casos mais otimistas, de parceria estratégica bilateral. Ademais, a relação intensa é devida, em grande parte, ao interesse comum estabelecido pelas redes sociais de migração, com projeção da cultura e das práticas sociais do país destino para o país de origem.

Essa pode ser considerada uma das frentes do exercício do soft power, ${ }^{20}$ e o

17 Seyla Benhabib, afirma: "Lejos de danar la cultura política de un pueblo y su constitución, los migrantes pueden revitalizarla y hacerla más profunda. Tal fue la contribución de liberales y socialista exiliados a las culturas políticas del siglo XIX de París y Londres; la cultura política estadounidense al fines del siglo XIX y comienzos del XX es en efecto impensable sin las contribuciones inmigrantes irlandeses, italianos, judío, polacos y otras comunidades. Y tampoco es concebible pensar en la universidad estadounidense en el período de la segunda posguerra sin tomar en cuenta las contribuciones de los mucho académicos europeos exiliados. Los movimientos migratorios por sí solos y sin las cruciales dislocaciones y tensiones que ya operan en las sociedades receptoras mismas, no amenazan la cultura política de un pueblo y sus principios constitucionales. (...) el desafío multicultural planteado al liberalismo político por el influjo de nuevos grupos inmigrantes lleva a una profundización y ampliación del programa de derechos en las democracias liberales. Los ‘derechos de los otros' no amenazan el proyecto del liberalismo político; por lo contrario, lo transforman hacia un proyecto democrático más inclusivo, dinámico y deliberativo". (BENHABIB, Seyla. Los derechos de los otros: extranjeros, residentes y ciudadano. Trad. Gabriel Zadunaisky. Barcelona: Gedisa, 2005, p. 73).

18 Amin Maalouf sustenta que “[N]ão será 'comunitarizando' os imigrantes que se vai facilitar a integração e se escapar dos 'confrontos' que se anunciam, mas sim restituindo a cada pessoa a dignidade cultural, a dignidade linguística, encorajando-a a assumir serenamente a dualidade identitária e o papel de traço de união" (MAALOUF, Amin. $O$ mundo em desajuste: quando nossas civilizações se esgotam. Trad. Jorge Bastos. Rio de Janeiro: DIFEL, 2011, p. 259).

19 Como afirma Douglas Massey na obra Return To Aztlan: The Social Process of International Migration From Western Mexico. Berkeley: University of California, 1987: "as redes migratórias consistem de laços sociais que ligam comunidades expulsoras a pontos específicos de destino nas sociedades receptoras. Esses laços unem migrantes e não migrantes em uma teia complexa de papéis sociais e relações interpessoais complementares, mantidos por conjuntos informais de expectativas recíprocas e comportamentos prescritos. (...) Esses laços sociais não são criados pelo processo migratório mas antes adaptados a ele, sendo reforçados, ao longo do tempo, através da experiência comum dos migrantes." apud FAZITO, Dimitri. A análise de redes sociais (ARS) e a migração: mito e realidade. Disponível em: <http://www.abep.nepo.unicamp.br/docs/anais/pdf/2002/gt_mig_st1_fazito_texto.pdf>. Acesso em: fev. 2015. p. 9.

20 Em artigo no site Project Syndicate, Nye explica “[e]qually important are immigration’s benefits for America’s soft 
consequente incremento da influência global do país destino. ${ }^{21} \mathrm{O}$ conceito de soft power é atribuído a Joseph Nye Jr. e significa, em termos gerais, o meio de cooptação e atração de alguém, ao invés de coerção, força militar ou transferência de dinheiro. Tem como fontes a cultura, os valores políticos e a política externa. É instrumento de política de Estado porque pode levar anos até seus resultados virem à tona. Ademais, é considerado mais difícil de gerir porque não está sob controle direto do governo, como o poder econômico e o poder militar, mas provém da cultura e dos valores "incorporados nas sociedades civis" (NYE JR., 2012, p.117-119).

No caso do Brasil, de acordo com os dados do IBGE, os Estados Unidos continuam a ser o principal destino de emigração dos brasileiros emigrantes.

O sentido desses deslocamentos se justifica uma vez que o Brasil se tornou espaço majoritariamente emissor de população nos anos de 1980, no auge da crise econômica. Nessa década, os Estados Unidos surgiram como principal área de atração de brasileiros, face ao seu status de grande potência econômica. A partir desses primeiros movimentos, redes sociais foram estabelecidas, proporcionando suporte a essa migração, atraindo um volume ainda maior de migrantes, mesmo após o arrefecimento do difícil momento econômico no Brasil (IBGE, 2011, p.6o).

A república brasileira, como "associação política formada por cidadãos livres e iguais", afirma Clèmerson Merlin Clève, perde a chance de participar do sistema mundial e, assim, projetar-se externamente como via de destino para refugiados e migrantes em busca de paz, trabalho e bem-estar enquanto não modifica o modo de tratamento da temática migratória. ${ }^{22}$

Como dito, considerando a perspectiva humanista na formulação e aplicação do novo Estatuto, o qual não mais teria como título "do Estrangeiro", mas, sim, "das Migrações", que passe a considerar a dignidade da pessoa humana como argumento central (CANÇADO TRINDADE, 2011, p. 145), substitui-se a pedra angular da segurança nacional pelo desenvolvimento humano (como liberdade na capacidade de se autodeterminar a partir de suas escolhas), e com este o nacional. Tais diretrizes só

\footnotetext{
power. The fact that people want to come to the US enhances its appeal, and immigrants' upward mobility is attractive to people in other countries. The US is a magnet, and many people can envisage themselves as Americans, in part because so many successful Americans look like them. Moreover, connections between immigrants and their families and friends back home help to convey accurate and positive information about the US. Likewise, because the presence of many cultures creates avenues of connection with other countries, it helps to broaden Americans' attitudes and views of the world in an era of globalization. Rather than diluting hard and soft power, immigration enhances both." (Immigration and American Power. Disponível em:

$<$ http://www.project-syndicate.org/commentary/obama-needs-immigration-reform-to-maintainamerica-s-strength-by-joseph-s--nye\#jhlSlwP3eMlOXEDE.99>. Acesso em jan. 2015).

21 Há também, por consequência, a contrapartida das redes de migração, pois “(...) passamos ao lado do essencial toda vez que deixamos de ver o 'emigrado’ por trás 'imigrante'. E cometemos um erro estratégico maior quando avaliamos o status dos imigrantes em função do lugar que eles ocupam nas sociedades ocidentais, quer dizer, frequentemente na parte mais baixa da escala social, e não em função do papel que têm - e que poderia ser cem vezes maior - em suas sociedades de origem, como vetores da modernização, do progresso social, da libertação intelectual, do desenvolvimento e da reconciliação." (MAALOUF, Amin. O mundo em desajuste: quando nossas civilizações se esgotam. Trad. Jorge Bastos. Rio de Janeiro: DIFEL, 2011, p. 253).
}

22 Dito no discurso sobre Políticas Migratórias e Reforma Legislativa no IV Seminário da Cátedra Sérgio Vieira de Mello (UFPR: 30.09.2013 - 10..10.2013). 
poderão ser implementadas quando se atentar para o estabelecimento de oportunidades de escolha para o migrante e, com isso, a sua condição de cidadania, pois "[a] sociedade democrática é aquela que não apenas garante os direitos individuais e coletivos historicamente conquistados, mas também os promove" (CLÈVE, 2011, p. 145).

Desse modo, crê-se que ao entender as instituições como "artefatos" da sociedade, que podem ser desconstruídas quando há mudança do contexto e da conjuntura, aclarase a noção de sua finitude. ${ }^{23}$ A continuação de um paradigma da década de 1950, pensado no contexto da Guerra Fria e aprimorado durante o regime militar que editou a lei do estrangeiro, não pode perdurar. Sua mudança é primordial para os interesses do Brasil em relação a sua política externa e a sua capacidade de receber migrantes a qual pode contribuir para a "vitalidade" da democracia.

O conceito de "vitalidade" de Roberto Mangabeira Unger determina a capacidade dinâmica infinita da sociedade de se renovar e se entender em comparação às instituições que foram e são criadas as quais, por outro lado, são finitas. "Não nos basta, porém, rever os contextos, ou rebelar-nos contra eles de vez em quando. É preciso criar contextos - modos de organizar a sociedade e o pensamento - de outro cunho: contextos que diminuam a distância entre atos corriqueiros com que nós os reproduzimos e os atos excepcionais com que nós os refazemos" (UNGER, 2011, p. 69).

Desse modo, o Brasil pode incrementar seu desenvolvimento com a renovada política migratória, a qual criaria um novo contexto. ${ }^{24}$ Propõe-se, com essa nova política, a substituição da atenção excessiva dada ao princípio da "segurança nacional" como eixo pivotal da legislação migratória, imposto por sua origem na Doutrina da Segurança Nacional, pelo princípio do desenvolvimento nacional como desenvolvimento humano. Daí decorre o argumento de que migrantes também fortalecem o desenvolvimento do país que os recebe. ${ }^{25}$ Nesse contexto, destacam-se os recentes encontros do Global Forum

23 A ideia é retirada do pensamento de Roberto Mangabeira Unger, particularmente nas obras: UNGER, Roberto Mangabeira. Política: os textos centrais, a teoria contra o destino. São Paulo: Boitempo; Santa Catarina: Argos, 20o1; e UNGER, Roberto Mangabeira. Necessidades falsas: introdução a uma teoria social antideterminista a serviço da democracia radical. São Paulo: Boitempo, 2005.

24 Também, no mesmo sentido de incremento do desenvolvimento humano e da sociedade receptora, os artigos do âmbito da Organização das Nações Unidas (ONU) KOPPENBERG, Saskia. Agents of development: how migrants contributes to achieve the MDGS (Millenium Development Goals) Disponível em: < http://internal-voices.blogspot. com.br/2010/12/agents-of-development-how-migrants.html >. Acesso em: jan. 2015; e do Representante Especial do Secretário-Geral da ONU para Migração e Desenvolvimento SUTHERLAND, Peter. Migration is development, de 15 mar. 2013. Disponível em: <http://www.project-syndicate.org/commentary/migrants-and-the-post-2015global-development-agenda-by-peter-sutherland>. Acesso em: jan. 2015. Este artigo amplia a ideia de correlação entre migrações e desenvolvimento e clama as sociedades a pensarem as migrações em suas políticas públicas como integrantes do novo "pacote" Objetivos do Milênio pós-2015 (quando acabará o prazo dos atuais). A apelação insere-se no contexto de discussões no próximo Diálogo de Alto-Nível das Nações Unidas sobre Migração Internacional a ser realizado em outubro de 2013.

25 A Lei de Migração (13.445/2017) segue, felizmente, esses pressupostos também já sustentados por nós alhures. Veja-se, por exemplo, os princípios e garantias veiculados no artigo $3^{\circ}$ que norteiam a interpretação e aplicação da referida lei ao caso concreto: "Art. $3^{\circ}$ A política migratória brasileira rege-se pelos seguintes princípios e diretrizes: I - universalidade, indivisibilidade e interdependência dos direitos humanos; (...) VII - desenvolvimento econômico, turístico, social, cultural, esportivo, científico e tecnológico do Brasil; (...) IX - igualdade de tratamento e de oportunidade ao migrante e a seus familiares; XI - acesso igualitário e livre do migrante a serviços, programas e benefícios sociais, bens públicos, educação, assistência jurídica integral pública, trabalho, moradia, serviço bancário e seguridade social; XII - promoção e difusão de direitos, liberdades, garantias e obrigações do migrante; (...) XX - 
on Migration E Development, particularmente os Informativos das reuniões de 2009 e 2010, na Grécia e no México, respectivamente. Essa renovada política tem a legislação como sua pedra angular, portanto, e pode projetar o Brasil internacionalmente como destino de famílias que, na busca por melhores oportunidades de vida (econômica, social, política), estabelecem importantes "redes sociais". ${ }^{26}$

\section{CONSIDERAÇÕES FINAIS}

A política pública brasileira das migrações precisa ser redefinida em termos argumentativos e institucionais. Seu atraso, sua instabilidade legislativa e seu descompromisso para com os direitos humanos e a proteção dos migrantes são patentes. Conquanto existam ações governamentais que a compatibilizem com o ordenamento jurídico fundado com a Constituição de 1988, sua diretriz e fundamento permanecem imobilizadas nosidos da década de1980. OEstatuto do Estrangeirodeveser compreendido como norteador da política pública das migrações, não apenas como mero regulamento de entrada e saída de estrangeiros no país. A ideologia presente no Estado autoritário que lhe deu origem, forma e conteúdo imprimiu sua marca na ação governamental posterior e, não por acaso, pode ser elencado como um dos fatores que contribuíram para a diminuição do fluxo imigratório para o Brasil.

Com o retorno do aumento do fluxo de imigrações, faz-se necessário renovar a política migratória. A revogação da lei 6.815/1980 e sua substituição por uma Lei das Migrações demanda o fim da antiga doutrina da segurança nacional e pode trazer as sementes para o crescimento do paradigma do desenvolvimento humano no seio da política migratória e da política externa brasileira.

Por fim, ainda que o discurso oficial tenha proposto uma transição "lenta e gradual" para a democracia no Brasil, isso não pode significar a imobilização das instituições com doutrinas autoritárias e a negação dos princípios fundamentais que devem nortear as políticas públicas nacionais.

Para tanto, mesmo com o distanciamento histórico das doutrinas autoritárias do cerne da administração pública nacional, a "renovação de credenciais" no que tange às

migração e desenvolvimento humano no local de origem, como direitos inalienáveis de todas as pessoas; (...)”. Para maior aprofundamento ver: KENICKE, Pedro Henrique Gallotti. O Estatuto do Estrangeiro e a Lei de Migrações: Da Doutrina da Segurança Nacional ao Desenvolvimento Humano. Curitiba: Edição do Autor, 2016. Disponível em: <https://www.academia.edu/27637134/O_Estatuto_do_Estrangeiro_e_a_Lei_das_Migra\%C3\%A7\%C3\%B5es_da_ Doutrina_da_Seguran\%C3\%A7a_Nacional_ao_Desenvolvimento_Humano>

26 O professor Dimitri Fazito de Almeida Rezende afirma que as redes sociais “[são] representaç[ões] de um sistema migratório onde determinadas regiões espaciais trocam pessoas, recursos materiais e informações, e estabelecem laços ou conexões sólidas que poderiam explicar a origem, o desenvolvimento e o recrudescimento de tais fluxos". REZENDE, Dimitri Fazito de Almeida. A análise de redes sociais (ARS) e a migração: mito e realidade. Disponível em: < http://www.abep.nepo.unicamp.br/docs/anais/pdf/2002/gt_mig_stı_fazito_texto.pdf >. Acesso em: jan. 2015. p. 9. Enfim, o último Relatório do Desenvolvimento Humano 2013, editado pelo Programa das Nações Unidas para o Desenvolvimento (PNUD), retoma o Relatório de 2009 para afirmar que a mobilidade internacional está, hoje, sendo integrada nas "estratégias de desenvolvimento nacional" pelos países e organizações do Sul, representando uma das frentes da Cooperação Sul-Sul (PNUD. Relatório do Desenvolvimento Humano 2013: A ascensão do Sul: progresso humano num mundo diversificado. New York: PNUD, 2013. p. 6o). 
instituições brasileiras que organizam a entrada e a vida dos imigrantes no país, ainda é necessária. O ajustamento e a atualização dos discursos institucionais teria como finalidade a substituição do ideário que trata o estrangeiro como um "inimigo" ou "ameaça" (doutrina da segurança nacional), por uma perspectiva que o trate como agente político, detentor de direitos e deveres, e potencial colaborador para o desenvolvimento socioeconômico do país (doutrina do desenvolvimento).

\section{REFERÊNCIAS}

BENHABIB, Seyla. Los derechos de los otros: extranjeros, residentes y ciudadano. Trad. Gabriel Zadunaisky. Barcelona: Gedisa, 2005.

BORGES, Nilson. A doutrina da segurança nacional e os governos militares. In: FERREIRA, Jorge; DELGADO, Lucilia de Almeida Neves (Orgs). O Brasil republicano: o tempo da ditadura: regime militar e movimentos sociais em fins do século XX. Rio de Janeiro: Civilização Brasileira, 2003.

BUCCI, Maria Paula Dallari. O conceito de política pública em direito. In: BUCCI, Maria Paula Dallari (Org.). Políticas públicas: reflexões sobre o conceito jurídico. São Paulo: Saraiva, 2006.

CANÇADO TRINDADE, Antônio Augusto. Desarraigamento e a proteção dos migrantes na legislação internacional dos direitos humanos. In: Revista da Faculdade de Direito da UFPR, v. 47, n. o, 2008.

CLÈVE, Clèmerson Merlin. Atividade legislativa do poder executivo. 3.ed., rev., atual. e ampl., São Paulo: Revista dos Tribunais, 2011.

. O direito e os direitos: elementos para uma crítica do direito contemporâneo. 3 ed. Belo Horizonte: Fórum, 2011. p. 145.

Direito Constitucional, novos paradigmas, constituição global e processos de integração. SAMPAIO, José Adércio Leite (Org.). 15 anos de Constituição. Belo Horizonte: Del Rey, 2004.

2012

Para uma dogmática constitucional emancipatória. Belo Horizonte: Fórum,

Política migratória e reforma legislativa. In: AGÊNCIA DA ONU PARA OS REFUGIADOS - ACNUR. IV Seminário da Cátedra Sérgio Vieira de Mello. Curitiba: UFPR, 30.09.2013 - 1º.10.2013.

Temas de direito constitucional. 2.ed. Belo Horizonte: Fórum, 2014. 
COMBLIN, Pe. Joseph. A ideologia da segurança nacional: o poder militar na América Latina. Trad. A. Veiga Fialho. Rio de Janeiro: Civilização brasileira, 1977.

FAZITO, Dimitri. A análise de redes sociais (ARS) e a migração: mito e realidade. Disponível em: < http://www.abep.nepo.unicamp.br/docs/anais/pdf/2002/gt_mig_st1_ fazito_texto.pdf > . Acesso em: jan. 2015.

FONSECA JR., Gelson. A legitimidade e outras questões internacionais. 2.ed. São Paulo: Paz e Terra, 2004.

INSTITUTO BRASILEIRODE GEOGRAFIAE ESTATÍSTICA(OIM). Censo Demográfico 2010: Características da população e dos domicílios. Rio de Janeiro: IBGE, 2011.

KENICKE, Pedro Henrique Gallotti. O Estatuto do estrangeiro e a lei de migrações: da doutrina da segurança nacional ao desenvolvimento humano. Curitiba: Edição do Autor, 2016. Disponível em: < https://www.academia.edu/27637134/O_Estatuto_ do_Estrangeiro_e_a_Lei_das_Migra\%C3\%A7\% $3 \% \mathrm{~B}_{5}$ es_da_Doutrina_da_ Seguran\%C3\%A7a_Nacional_ao_Desenvolvimento_Humano > Acesso em: ago. 2013.

KOPPENBERG, Saskia. Agents of development: how migrants contributes to achieve the MDGS (Millenium Development Goals). Disponível em: < http://internal-voices. blogspot.com.br/2010/12/agents-of-development-how-migrants.html > Acesso em: ago. 2013.

MAALOUF, Amin. O mundo em desajuste: quando nossas civilizações se esgotam. Trad. Jorge Bastos. Rio de Janeiro: DIFEL, 2011.

NYE JR., Joseph. Soft Power: the means to success in world politics. New york: Public Affairs, 2004.

. O futuro do poder. Trad. Magda Lopes. São Paulo: Benvirá: 2012.

Immigration and American power. Disponível em:

< http://www.project-syndicate.org/commentary/obama-needs-immigration-reformto-maintain-america-s-strength-by-joseph-s--nye\#jhlSlwP3eMlOXEDE.99 >. Acesso em jan. 2015.

ORGANIZAÇÃO INTERNACIONAL PARA AS MIGRAÇÕES (OIM). Informe sobre las migraciones en el mundo: el bienstar de los migrantes y el desarollo. 2013. 
PROGRAMA DAS NAÇÕES UNIDAS PARA O DESENVOLVIMENTO (PNUD). Relatório do Desenvolvimento Humano 2o13: A ascensão do Sul: progresso humano num mundo diversificado. New York: PNUD, 2013.

RAMOS, André de Carvalho. Direitos dos estrangeiros no Brasil: a imigração, direito de ingresso e is direitos dos estrangeiros em situação irregular. In: SARMENTO, Daniel; IKAWA, Daniela; PIOVESAN, Flávia. Igualdade, diferença e direitos humanos. Rio de Janeiro: Lumen Juris, 2008.

REZENDE, Dimitri Fazito de Almeida. A análise de redes sociais (ARS) e a migração: mito e realidade. Disponível em: < http://www.abep.nepo.unicamp.br/docs/anais/ pdf/2002/gt_mig_stı_fazito_texto.pdf >. Acesso em: ago. 2013.

SARAIVA, José Flávio Sombra. Dois gigantes e um condomínio: da guerra fria à coexistência pacífica (1947-1968). In: SARAIVA, José Flávio Sombra (Org.). História das relações internacionais contemporâneas: da sociedade internacional do século XIX à era da globalização. 2.ed. São Paulo: Saraiva, 2008.

SEN, Amartya. Desenvolvimento como liberdade. Trad. Laura Teixeira Motta. São Paulo: Companhia das Letras, 2000.

Desigualdade reexaminada. trad. Ricardo Doninelli Mendes. 3.ed. Rio de Janeiro: Record, 2012.

The idea of justice. Cambridge: Harvard University, 2009.

SICILIANO, André Luiz. A política migratória brasileira: limites e desafios. São Paulo: USP-IRI, 2013.

SILVA, João Guilherme Lima Granja Xavier da. Política migratória e reforma legislativa. In: AGÊNCIA DA ONU PARA OS REFUGIADOS - ACNUR. IV Seminário da Cátedra Sérgio Vieira de Mello. Curitiba: UFPR, 30.09.2013 - $1^{0} \stackrel{0}{0.10 .2013 .}$

SUTHERLAND, Peter. Migration is development, de 15 mar. 2013. Disponível em: < http://www.project-syndicate.org/commentary/migrants-and-the-post-2015-globaldevelopment-agenda-by-peter-sutherland >. Acesso em: ago. 2013.

TIBURCIO, Carmen. A condição jurídica do estrangeiro na Constituição brasileira de 1988. In: SARMENTO, Daniel; IKAWA, Daniela; PIOVESAN, Flávia. Igualdade, diferença e direitos humanos. Rio de Janeiro: Lumen Juris, 2008. 
VENTURA, Deisy; ILLES, Paulo. Estatuto do estrangeiro ou lei de imigração?. In: Le Monde Diplomatique, $1^{\circ}$ ago. 2010. Disponível em: < http://www.diplomatique.org.br/ artigo.php?id=744 >. Acesso em: fev. 2015 .

UNGER, Roberto Mangabeira. A constituição do experimentalismo democrático. In: Revista de Direito administrativo, v. 257, maio/agosto, 2011.

Política: os textos centrais, a teoria contra o destino. São Paulo: Boitempo; Santa Catarina: Argos, 2001.

Necessidades falsas: introdução a uma teoria social antideterminista a serviço da democracia radical. São Paulo: Boitempo, 2005.

UNITED NATIONS. International migration report 2009: a global assessement. New York: Department of Economic and Social Affairs - Population Division, dec. 2011. 